\section{Commentary: Aristotle, the truth, and cone reconstruction}

\author{
David M. Overman, MD \\ "To say of what is that it is not, or of what is not that it \\ is, is false, while to say of what is that it is, and of what \\ is not that it is not, is true."
}

-Aristotle

The Correspondence Theory of Truth, with which Aristotle is associated, in short holds that truth becomes evident when supported by fact, and cannot exist absent such fact. Its implication is that there are discrete and definable rules about declaring something true, and we imperil our connection to the truth if we do not observe them. It is instructive to recall this principle when assessing what we presently know and do not know about the cone repair, the influence of which on surgical therapy for Ebstein anomaly promises to be enormous.

The report from Burri and colleagues ${ }^{1}$ is a notable milestone in the emergence of the cone repair as the procedure of choice for Ebstein anomaly. First, it demonstrates independently reproducible and superb results using an operation with a documented learning curve. ${ }^{2}$ Second, extensive medium-term echocardiographic follow-up (a particular strength of this cohort) reveals a significantly lower incidence of residual disease after cone repair compared with other repair techniques or replacement. Third, the procedure was successfully performed in $95 \%$ of attempts, with only 1 failure. This stands in marked contrast to the authors' pre-cone experience as well as that reported in historical series, where valve replacement was required in a substantial percentage of patients. ${ }^{3}$ That, then, is what one may "say of what is that it is" regarding cone reconstruction.

From the Division of Cardiovascular Surgery, Children's Minnesota, Mayo Clinic-Children's Minnesota Cardiovascular Collaborative, and the Division of Cardiac Surgery, The Children's Heart Clinic, Minneapolis, Minn.

Disclosures: The author reported no conflicts of interest.

The Journal policy requires editors and reviewers to disclose conflicts of interest and to decline handling or reviewing manuscripts for which they may have a conflict of interest. The editors and reviewers of this article have no conflicts of interest.

Received for publication June 9, 2020; accepted for publication June 11, 2020; available ahead of print June 29, 2020.

Address for reprints: David M. Overman, MD, Division of Cardiac Surgery, The Children's Heart Clinic, 2530 Chicago Ave, S, Suite 500, Minneapolis, MN 55404 (E-mail: doverman@chc-pa.org).

J Thorac Cardiovasc Surg 2020;160:1556-7

0022-5223/\$36.00

Copyright (c) 2020 by The American Association for Thoracic Surgery

https://doi.org/10.1016/j.jtcvs.2020.06.075

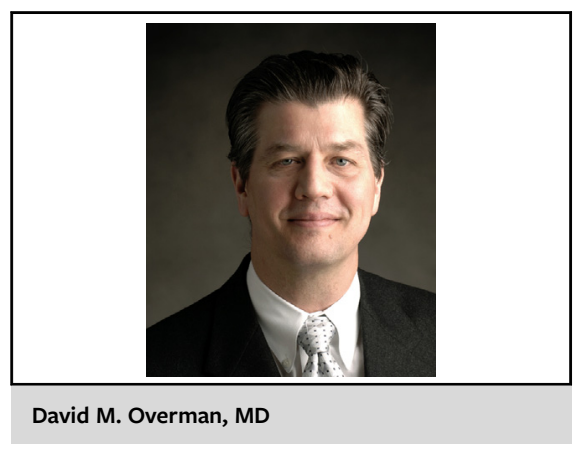

CENTRAL MESSAGE

Emergence of the cone repair is a milestone in the surgical treatment of Ebstein anomaly. Yet fulfillment of its promise requires more accumulated experience and long-term outcome data.

However, just as important to understanding truth is saying "of what is not that it is not."

An important weakness of this report is the significantly smaller size of the cone repair cohort and, more importantly, its significantly shorter follow-up (median, 3.7 years). This is a common feature of the extant literature on cone reconstruction. Outside of the Mayo Clinic's enormous experience, most series number in the 20 s or teens. The longest median follow-up in any series published is 57 months, ${ }^{4}$ and in most it is 4 years or fewer. Finally, most series have significantly less robust echo follow-up data compared with this report. "What is not" when it comes to cone reconstruction, then, is that documented experience with the procedure is relatively modest and long-term survival and valve performance data are still lacking.

It is appropriate to celebrate the genius of design and the published clinical track record of cone reconstruction, and there is no doubt the procedure is here to stay. Indeed, it is tempting to declare all other techniques irrelevant and install the cone repair as the definitive answer to the challenge of Ebstein anomaly. But that would be meandering from the truth, saying "of what is not, that it is." The early signs are indeed compelling, and medium-term follow-up continues to affirm the impression. But to know the definitive truth about the cone repair, we must patiently await a sufficiently broad experience and, more importantly, longer-term outcomes. 


\section{References}

1. Burri M, Mrad Agua K, Cleuziou J, Beran E, Nagdyman N, Kuhn A, et al. Cone versus conventional repair for Ebstein's anomaly. J Thorac Cardiovasc Surg. 2020;160:1545-53

2. Dearani JA, Said SM, O'Leary PW, Burkhart HM, Barnes RD, Cetta F. Anatomic repair of Ebstein's malformation: lessons learned with cone reconstruction. Ann Thorac Surg. 2013;95:220-6.
3. Brown ML, Dearani JA, Danielson GK, Cetta F, Connolly HM, Warnes CA. The outcomes of operations for 539 patients with Ebstein anomaly. J Thorac Cardiovasc Surg. 2008;135:1120-36.

4. da Silva JP, Baumgratz JF, da Fonseca L, Afiune JY, Franchi SM, Lopes LM, et al Ebstein's anomaly (results of the conical reconstruction of the tricuspid valve). Arq Bras Cardiol. 2004;82:212-6.
See Article page 1545 .

\section{Commentary: Should the cone repair be the only option to consider for all patients with Ebstein's anomaly? Definitely not}

\author{
David Kalfa, MD, PhD
}

In this issue of the Journal, the group from Munich, Germany, describe the outcomes of their surgical series in patients with Ebstein's anomaly. ${ }^{1}$ Their aim was to investigate short-term and long-term outcomes (including tricuspid regurgitation, reoperation, and death) following conventional repair of Ebstein's anomaly and compare the results with the cone repair.

They demonstrate a clear advantage of the cone repair over conventional repair at a follow-up of 5 years. The 2 take-home messages are: (1) failed valve repair (that they define as in-hospital death, conversion to replacement, or in-hospital reoperation) is significantly less frequent after the cone repair (5\%) than after other repair techniques $(20 \%)$; and (2) the 5-year cumulative incidence of recurrent tricuspid regurgitation moderate or greater is significantly lower after the cone repair $(8 \%)$

\footnotetext{
From the Section of Pediatric and Congenital Cardiac Surgery, Division of Cardiac, Thoracic and Vascular Surgery, New York-Presbyterian Morgan Stanley Children's Hospital, Columbia University Medical Center, New York, NY.

Disclosures: The author reported no conflicts of interest.

The Journal policy requires editors and reviewers to disclose conflicts of interest and to decline handling or reviewing manuscripts for which they may have a conflict of interest. The editors and reviewers of this article have no conflicts of interest.

Received for publication June 16, 2020; revisions received June 16, 2020; accepted for publication June 16, 2020; available ahead of print June 24, 2020.

Address for reprints: David Kalfa, MD, PhD, Pediatric Cardiac Surgery, New YorkPresbyterian Morgan Stanley Children's Hospital, Columbia University Medical Center, New York, NY 10032 (E-mail: dk2757@cumc.columbia.edu).

J Thorac Cardiovasc Surg 2020;160:1557-8

$0022-5223 / \$ 36.00$

Copyright (c) 2020 by The American Association for Thoracic Surgery

https://doi.org/10.1016/j.jtcvs.2020.06.011
}

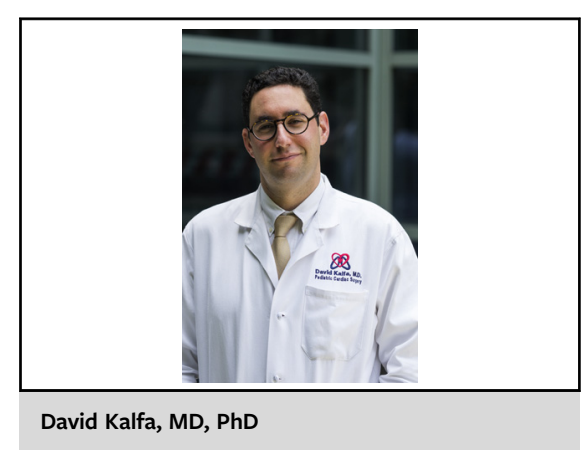

CENTRAL MESSAGE

The cone repair dramatically improved the short-term and mid-term outcomes for patients with Ebstein's anomaly but a lot still needs to be learned on longterm outcomes and patient selection.

than after other repair techniques $(32 \%)$. These points are not arguable.

Nevertheless, this series has some significant limitations that the authors acknowledge quite well. The most important limitation is the significantly shorter follow-up of the cone group compared with the conventional group. This limitation prevents the authors from drawing any conclusions on the long-term assumed superiority of the cone over the conventional techniques. Moreover, the subjective and operator-dependent assessment of tricuspid regurgitation on echocardiography without objective measurement of the vena contracta in the setting of a retrospective single-center study brings more concerns about the reliability of the findings.

That being said, this nice study confirms the impression that almost all of us, cardiac surgeons taking care of this difficult and challenging population, share: the cone repair 